\title{
Meningkatkan Hasil Belajar Bahasa Indonesia Materi Memahami Teks Pendek Dan Puisi Dengan Menggunakan Metode Drill Pada Peserta Didik Kelas II SDN 1 Mekar Indah Tahun Pelajaran 2019/2020
}

\author{
Surantoso \\ SDN 1 Mekar Indah \\ Kuala Pembuang, Indonesia \\ (Diterima 17-10-2019; Disetujui 20-11-2019)
}

\begin{abstract}
ABSTRAK
Penelitian Tindakan Kelas (PTK) guna meningkat hasil belajar penjasorkes. Subjek dalam penelitian ini adalah seluruh peserta didik kelas II pada SDN 1 Sungai Undang, yang terdiri dari 21 orang peserta didik. Untuk teknik pengumpulan data yang digunakan adalah observasi dan tes. Penelitian ini menggunakan analisis nilai rata-rata kelas dan persentase ketuntasan belajar individu dan secara klasikal. Ada hasil pembelajaran pada pembelajaran awal sebelum tindakan persentase ketuntasan adalah 52\%, dengan dilakukannya tindakan pembelajaran metode pembelajaran Menggunakan Metode Drill pada siklus I meningkat menjadi 67\%, dan pada siklus II dengan persentase aktivitas pemBelajaran memenuhi standar ketuntasan efektifitas belajar mencapai $100 \%$. Ada Peningkatan hasil pembelajaran data awal diperoleh nilai rata-rata pembelajaran dari 69,33 pra tindakan pembelajaran, setelah dilaksanaan pembelajaran dengan metode Menggunakan Metode Drill meningkat menjadi 71,62 pada siklus I dengan persentase ketuntasan 67\%. Pada Siklus II ratarata nilai meningkat menjadi 75,48
\end{abstract}

Kata Kunci: Hasil belajar, Bahasa Indonesia, Metode Drill

\section{PENDAHULUAN}

Pendidikan merupakan landasan dalam pengembangan praktik pendidikan, misalnya pengembangan kurikulum, proses belajar-mengajar dan manajemen sekolah. Kurikulum dan pembelajaran memiliki keterkaitan dengan teori pendidikan atau dalam penyusunan suatu kurikulum dan rencana pembelajaran ini mengacu pada teori pendidikan. Teori pendidikan ini dibagi menjadi empat, yaitu pendidikan klasik, pendidikan personal, teknologi pendidikan, dan pendidikan interaksional. Pendidikan klasik berlandaskan pada filsafat klasik, seperti perenialisme, essensialisme, dan eksistensialisme, yang memandang bahwa pendidikan berfungsi sebagai upaya memelihara, mengawetkan dan meneruskan warisan budaya. Pendidikan ini lebih menekankan pada peranan isi pendidikan dari pada proses. Isi pendidikan atau materi diambil dari khasanah ilmu pengetahuan yang ditemukan dan dikembangkan para ahli tempo dulu yang telah disusun secara logis dan sistematis. Selain itu pendidikan klasik menjadi sumber bagi pengembangan metode kurikulum subjek akademis, yaitu kurikulum yang bertujuan memberikan pengetahuan yang solid serta melatih peserta didik menggunakan ide-ide dan proses "penelitian" melalui metode ekspositori dan inkuiri.

Metode ekspositori merupakan Metode pembelajaran yang menekankan pada proses penyampaian materi secara verbal dari seorang guru kepada sekelompok siswa dengan maksud supaya siswa dapat menguasai materi pelajaran secara optimal, sedangkan metode inkuiri yakni metode pembelajaran yag menekankan pada mencari dan menemukan, maksudnya siswa berperan aktif untuk mencari dan menemukan jawaban sendiri dari suatu masalah yang dipertanyakan, 
sehingga guru hanya berperan sebagai fasilitator dan membimbing siswa untuk belajar.Bertolak dari asumsi bahwa sejak lahir anak telah memiliki potensi-potensi tertentu. Pendidikan harus dapat mengembangkan bakat-bakat atau potensi yang dimiliki setiap anak dengan bertolak dari kebutuhan dan minat peserta didik. Sehingga peserta didik menjadi pelaku utama dalam pendidikan, sedangkan pendidik menempati posisi kedua yakni berperan sebagai pembimbing, pendorong, fasilitator, dan pelayanan peserta didik.

Teknologi pendidikan merupakan suatu konsep pendidikan yang mempunyai persamaan dengan pendidikan tentang peranan pendidikan dalam menyampaikan informasi. pada kemampuan vokasional. Isi disusun dalam bentuk desain pengajaran dan disampaikan dengan menggunakan media elektronik, dan para peserta didik belajar secara individual. Sehingga pendidik berfungsi sebagai direktur belajar, lebih banyak pada tugas-tugas pengelolaan daripada penyampaian dan pendalaman bahan. Teknologi pendidikan menjadi sumber berkembangnya metode kurikulum yakni metode kurikulum yang bertujuan memberikan penguasaan kompetensi bagi peserta didik, sehingga pembelajarannya menggunakan media pembelajaran individual, media buku maupun media elektronik.

Pada saat ini di SDN 1 Sungai Undaang Kecamatan Seruyan Hilir pembelajaran Bahasa Indonesia dalam tematik Memahami teks pendek dan puisi mengalami kesulitan karena susah dalam menghafal sehingga banyak tidak mengerti walaupun hafal karena arahan pertanyaan yang mereka tidak fahami sehingga salah dalam menjawab pertanyaan yang diberikan guru. Setelah ditanya kenapa mereka banyak menjawab pertanyaan mereka menjelaskan bahwa belum tahu yang mereka pelajari hanya sekedar menghafal dan tidak tahu secara pastu apa bagian - bagian utama tubuh hewan, tumbuhan karena itulah mereka ingin melihat secara langsung agar mereka memahami pembelajaran tersebut. Setelah dilakukan pembelajaran remedial untuk materi tersebut dan dilakukan evaluasi kembali ternya hasil pembelajarannya masih belum memuaskan karena dari 21 orang peserta didik diperoleh 11 orang tuntas dan 10 orang tidak tuntas.

\section{METODE PENELITIAN}

Penelitian ini dilaksanakan dari bulan Juli 2018 sampai dengan Oktober 2018, bertempat di SDN 1 Sungai Undaang yang beralamat di jalan Sungai Undang Kecamatan Seruyan Hilir Kabupaten Seruyan Kalimantan Tengah. Subjek penelitian pada penelitian ini adalah peserta didik SDN 1 Sungai Undaang yaitu peserta didik yang duduk di Kelas II sebanyak 21 siswa. Berdasarkan tujuan penelitian untuk meningkatkan hasil belajar Bahasa Indonesia Kelas II Sekolah Dasar maka jenis penelitian yang dilakukan peneliti adalah Penelitian Tindakan Kelas (PTK). Penelitian Tindakan Kelas (PTK) adalah penelitian yang dilakukan guna meningkatkan hasil belajar yang sesuai dengan kondisi sekolah agar masalah belajar yang dihadapi sekolah dapat dituntaskan dengan baik. Langkah-langkah Penelitian Tindakan Kelas (PTK) adalah mulai dari identifikasi masalah, perencanaan tindakan, pelaksanaan tindakan, dan refleksi hasil pengumpulan data pelaksanaan tindkan pada tahapan siklus I dan hasil refleksi siklus I dilakukan perbaikan dan dilanjutkan kesiklus II

Rencana penelitian yang akan dilaksanakan berdasarkan studi awal identifikasi masalah sampai dengan tindakan berupa pembelajaran Bahasa Indonesia dengan menggunakan Metode Drill dilaksanakan dalam beberapa siklus sampai dengan tercapainya tujuan penelitian dengan adanya peningkatan hasil belajar dengan ketuntasan belajar individual sesuai KKM mata pelajaran Bahasa Indonesia yaitu 65 dengan ketuntasan klasikal $\geq 85 \%$.

Tahapan-tahapan yang akan dilakukan dalam penelitian ini adalah sebagai berikut: Menyusun perangkat pembelajaran RPP, Silabus, Agenda Mengajar, Jurnal kelas, dan bahan Tes evaluasi belajar beserta Lembar Pengamatan dan Pedoman Wawancara, Menyusun jadwal kegiatan. 
Mempersiapkan alat dan bahan yang diperlukan selama proses pembelajaran. Tindakan Pada tahap ini dilaksanakan proses pembelajaran sesuai dengan deain yang disusun. Dalam pelakaanaannya, semua instrument yang telah dipersiapkan dengan baik dguinakan sesrencanaannya. Observasi Pengamatan dilakukan secara bertahap, dari persiapan, pelaksanaan, pelaporan hasil pembahasan. Agar pengamatan bisa memberi arah digunakan lembar pengamatan yang telah disusun.

Refleksi dilakukan pada akhir tiap siklus diadakan refleksi berdasarkan data observasi, dengan refleksi ini dimaksudkan agat peneliti dapat melihat apakah kegiatan yang dilakukan dapat meningkatkan prestasi belajar peserta didik, dan ada perubahan perilaku peserta didik. Proses tindakan siklus dimulai dari sklus I dilanjutkan dengan pemnyempurnaan ke siklus II dengan tahapan-tahapan yang sesuai dengan yang dilakukan dalam siklus I. Perbaikan pada sklus selanjutnya dapat dilakukan pada perangkat pembelajaran RPP, Silabus, Buku pegangan dan alat evaluasi soal tes dan Lembar Pengamatan, peyesuaian jadwal kegiatan, alat dan bahan, sumber, dan aspek yang berkait dengan pelaksanan metode pembelanjaran.

Pengumpulan data dalam penelitian tindakan kelas ini menggunakan instrumen yang terdiri dari Lembar Observasi dan Tes Kemampuan, merupakan teknik pengumpulan data yang dilakukan dengan cara mengamati secara langsung terhadap kegiatan pelaksanaan dari rancangan tindakan. Tes kemampuan peserta didik diberikan untuk mengukur kemampuan daya serap pembelejaran setelah dilakukan tindakan pembelajaran dengan metode Menggunakan Metode Drill dengan acuan ketuntasan belajar sesuai KKM mata pelajaran secara individual dan klasikal.

Data yang diperoleh dalam bentuk kualitatif baik dari hasil pengamatan maupun wawancara menggunakan analisis deskriptif kualitatif berdasarkan hasil observasi dan refleksi dari tiap-tiap siklus. Prosedur penelitian tindakan ini terdiri dari beberapa siklus penelitian dengan tujuan pembelajaran yang dimuat dalam Rencana Pelaksanaan Pembelajaran (RPP) dengan teknik analisis data kualitatif.

\section{HASIL DAN PEMBAHASAN}

Hasil belajar dari 21 yang terdiri 11 orang peserta didik laki-laki dan 10 orang peserta didik perempuan. Pada obesrvasi awal penilaian aktivitas belajar peserta didik pada data awal sebelum dilakukan tindakan pembelajaran dengan menggunakan metode pembelajaran Menggunakan Metode Drill persentase aktivitas belajar 63\% dibawah kriteria ketuntasan aktivitas belajar $\geq 85 \%$ untuk katagori kurang.

Tabel 1. Data Awal Aktivitas Belajar dan ketuntasan

\begin{tabular}{lccccc}
\hline \multirow{2}{*}{ Pencapaian } & \multicolumn{3}{c}{ Aktifitas } & \multicolumn{2}{c}{ Ketuntasan } \\
& Baik & cukup & Kurang & Tuntas & Tidak \\
\hline Frekuensi & 11 & 5 & 5 & 11 & 10 \\
Persentase & $52 \%$ & $24 \%$ & $24 \%$ & $52 \%$ & $48 \%$ \\
Jumlah & \multicolumn{3}{c}{$100 \%$} & \multicolumn{2}{c}{$100 \%$} \\
\hline
\end{tabular}

Berdasarkan data penilaian aktivitas pembelajaran dengan tiga katagori penilaian; Baik sebanyak 11 orang atau $52 \%$, bernilai cukup sebanyak 5 orang atau $24 \%$, dan penilaian kurang sebanyak 5 orang atau 24\%, Aktivitas awal untuk kriteria Baik 6 orang atau $50 \%$, ini berarti masih dibawah standar ketuntasan $\geq 85 \%$, dalam katagori diatas secara klasikal belum bisa memenuhi ketuntasan minimum termasuk rendah. Berikut diagram aktivitas awal sebelum dilaksanakan pembelajaran metode Menggunakan Metode Drill. 


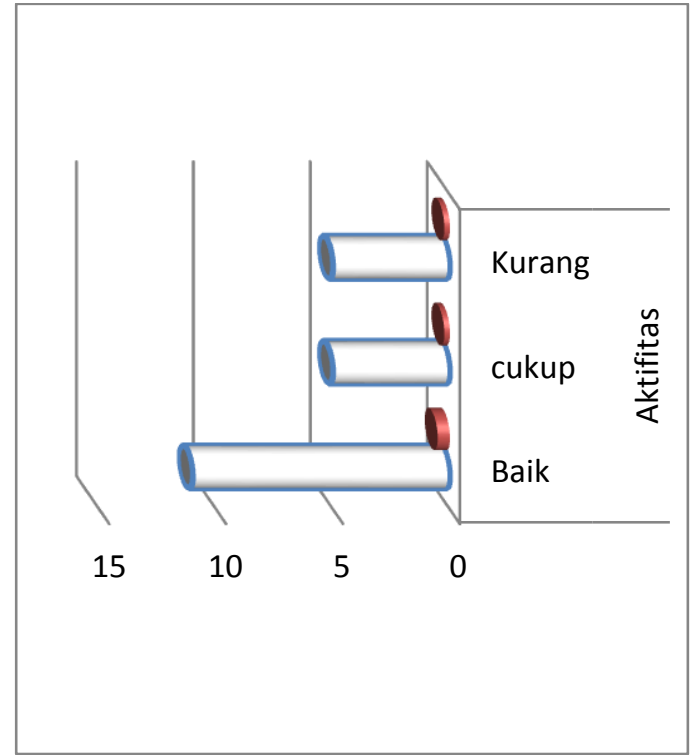

Gambar 1. Observasi awal

Sedangkan pendataan data awal hasil pembelajaran sebelum dilaksanakan tindakan pembelajaran dengan metode Menggunakan Metode Drill

Tabel 2. Data awal Hasil Belajar

\begin{tabular}{|c|c|c|c|}
\hline No & Kode Peserta Didik & Nilai & Ketuntasan \\
\hline 1 & ADIT M. SAPUTRA & 75 & Tuntas \\
\hline 2 & AFRIZAL & 60 & Tidak \\
\hline 3 & AHMAD FADILAH & 68 & Tuntas \\
\hline 4 & ALI SAID & 60 & Tidak \\
\hline 5 & ALISA & 60 & Tidak \\
\hline 6 & AMINUL HUSNAWATI & 78 & Tuntas \\
\hline 7 & AULIA ARISQA & 68 & Tuntas \\
\hline 8 & AULIA SAPITRI & 80 & Tuntas \\
\hline 9 & DESI & 60 & Tidak \\
\hline 10 & EDI & 60 & Tidak \\
\hline 11 & ERLIN ERLIANA & 60 & Tidak \\
\hline 12 & KADIRAN & 78 & Tuntas \\
\hline 13 & MARIYA ULFAH & 80 & Tuntas \\
\hline 14 & MEILIYA HIDAYAT & 64 & Tidak \\
\hline 15 & NABILA & 78 & Tuntas \\
\hline 16 & NAURA SAL SABILLA & 64 & Tidak \\
\hline 17 & PUTRI NUR DANDI & 80 & Tuntas \\
\hline 18 & PUTRI NUR VIKA & 64 & Tidak \\
\hline 19 & REMANIA RAHMADANI & 78 & Tuntas \\
\hline 20 & RIFAN NURYANDA & 78 & Tuntas \\
\hline 21 & RIMA RIMBANI & 63 & Tidak \\
\hline
\end{tabular}


Sedangkan untuk ketuntasan belajar untuk data diperoleh sebanyak 11 orang atau $52 \%$ dan tidak tuntas sebanyak 10 orang atau $48 \%$ dengan rata-rata nilai 69,33, untuk lebih jelasnya Berikut diagram ketuntasan data awal sebelum dilakukan tidanakan pembelajaran dengan menggunakan Metode Drill.

\section{Pembahasan Siklus I}

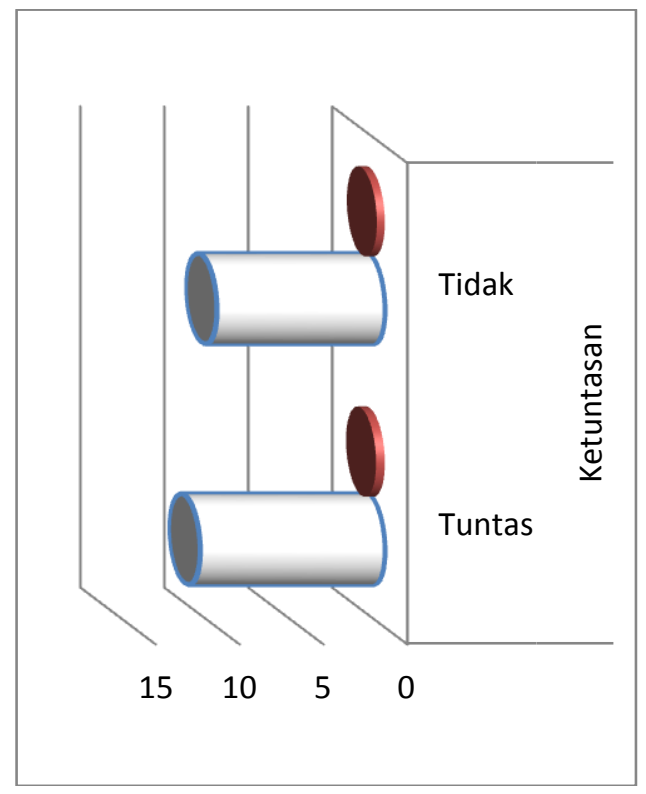

Gambar 2. Grafik Ketuntasan belajar Pra Tindakan

Pada siklus ini melalui observasi awal, terlihat gambaran apa saja yang harius dilakukan pada siklus I. Pemberian pembelajaran awal dan pre tes pengamat dan guru, memberikan kontribusi penilaian terhadap objek penelitian. pembelajaran. Berikut hasil pembelajaran siklus I Tabel 3 Aktivitas Belajar Siklus I

\begin{tabular}{cccc}
\hline Aktivitas & Baik & Cukup & Kurang \\
\hline Frekuensi & 14 & 4 & 1 \\
Persentase & $67 \%$ & $19 \%$ & $14 \%$ \\
\hline
\end{tabular}

Hal-hal penting dan perkembangan kemajuan pada saat pembelajaran siklus I meliputi penguasaan materi pengajaran dan kemajuan serta aktivitas peserta didik saat pembelajaran. Berikut hasil pembelajaran siklus I meliputi aktivitas peserta didik seperti Minat dan motivasi belajar diperoleh data 14 orang temasuk aktiv dengan persentase $67 \%$

Pengmatan pembelajaran siklus I peserta yang memperhatikan pelajaran yang diberikan oleh guru mencapai $67 \%$, dan Kemampuan menyelesaikan tugas yang diberikan mencapai $67 \%$ untuk kriteria Baik masih belum mencukupi persentase $\geq 85 \%$, dan 4 orang cukup aktiv dengan persentase $19 \%$, dan dinilai kurang 1 orang atau persentasenya $14 \%$, sehingga perlu perbaikan dari segi pengamatan yaitu; materi perlu diperjelas lagi dalam pembimbingan dan pemahaman dalam RPP perlu ditambahkan rincian alur pembelajaran, latihan perlu dimuat sehingga tujuan pembelajaran Menggunakan Metode Drill lebih jelas lagi, dan terakhir perlu lembar kerja peserta didik sehingga memudahan dalam mencatat kegiatan. Berikut diagram aktivitas belajar siklus I 


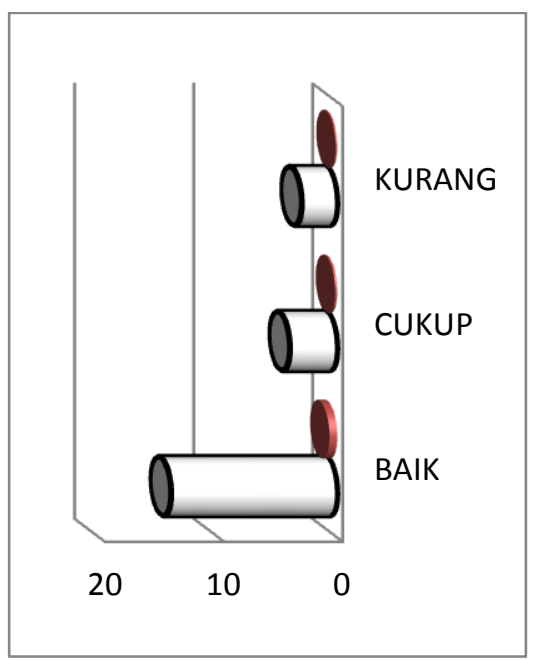

Gambar 4 . Diagram Aktivitas Belajar Siklus I

Berikut hasil pembelajaran siklus I setelah dilakukan tindakan pembelajaran dengan metode pembelajaran Menggunakan Metode Drill

Tabel 4. Hasil pembelajaran siklus I

\begin{tabular}{|c|c|c|c|}
\hline No & Kode Peserta Didik & Nilai & Ketuntasan \\
\hline 1 & ADIT M. SAPUTRA & 75 & Tuntas \\
\hline 2 & AFRIZAL & 64 & Tidak \\
\hline 3 & AHMAD FADILAH & 68 & Tuntas \\
\hline 4 & ALI SAID & 63 & Tidak \\
\hline 5 & $\begin{array}{l}\text { ALISA } \\
\text { AMINUL }\end{array}$ & 64 & Tidak \\
\hline 6 & HUSNAWATI & 78 & Tuntas \\
\hline 7 & AULIA ARISQA & 68 & Tuntas \\
\hline 8 & AULIA SAPITRI & 80 & Tuntas \\
\hline 9 & DESI & 68 & Tuntas \\
\hline 10 & EDI & 64 & Tidak \\
\hline 11 & ERLIN ERLIANA & 70 & Tuntas \\
\hline 12 & KADIRAN & 78 & Tuntas \\
\hline 13 & MARIYA ULFAH & 80 & Tuntas \\
\hline 14 & MEILIYA HIDAYAT & 70 & Tuntas \\
\hline 15 & $\begin{array}{l}\text { NABILA } \\
\text { NAURA SAL }\end{array}$ & 78 & Tuntas \\
\hline 16 & SABILLA & 64 & Tidak \\
\hline 17 & PUTRI NUR DANDI & 80 & Tuntas \\
\hline 18 & $\begin{array}{l}\text { PUTRI NUR VIKA } \\
\text { REMANIA }\end{array}$ & 68 & Tuntas \\
\hline 19 & RAHMADANI & 78 & Tuntas \\
\hline 20 & RIFAN NURYANDA & 78 & Tuntas \\
\hline 21 & $\begin{array}{c}\text { RIMA RIMBANI } \\
\text { Rata-Rata }\end{array}$ & $\begin{array}{c}68 \\
71.62\end{array}$ & Tuntas \\
\hline
\end{tabular}


Berdasarkan hasil pembelajaran siklus I diperoleh nilai rata-rata pembelajaran dari 70,79 meningkat menjadi 73,16 dengan persentase ketuntasan. Berikut grafik ketuntasan belajar siklus I

Tabel 5. Ketuntasan Belajar Siklus I

\begin{tabular}{ccc}
\hline Ketuntasan & Tuntas & Tidak \\
\hline Frekuensi & 14 & 5 \\
Persentase & $67 \%$ & $24 \%$ \\
\hline
\end{tabular}

Berdasarkan hasil pembelajaran siklus I diperoleh nilai persentase ketuntasan pembelajaran awal dari 11 orang atau 52\% meningkat pada siklus I meningkat menjadi tuntas 14 orang atau $67 \%$ dengan persentase ketuntasan. Berikut grafik ketuntasan belajar siklus I

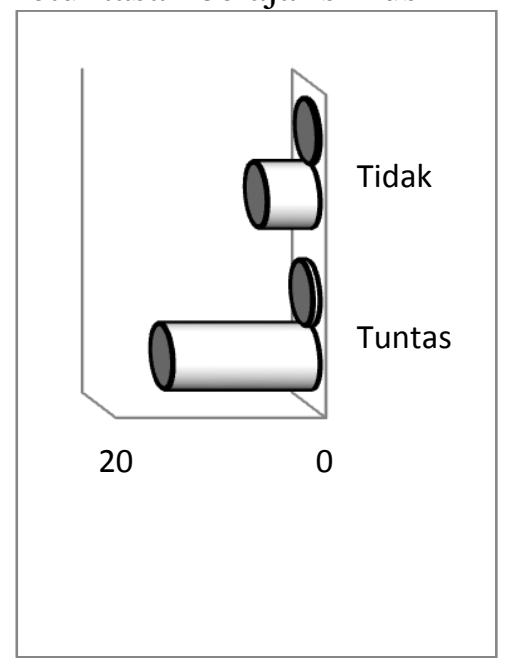

Gambar 5. Hasil Pembelajaran Siklus I

Penilaian berdasarkan pengamatan oleh observer dilakukan evaluasi masih ada 5 orang yang belum tuntas sehingga perlu perbaikan pembelajaran atas 5 orang peserta didik tersebut yaitu meliputi ketercapaian metode dan kekurangnya pada saat pembelajaran siklus I. Kekurangan dan kendala yang dihadapi pada siklus I ini dilakukan perbaikan pada siklus II.

\section{Pembahasan Siklus II}

Pada siklus ini adalah perbaikan atau wujud refleksi dari siklus sebelumnya agar dilakukan perbaikan dan revisi yang menjadi kendala serta menutupi segala kekurangan pada pembelajaran sebelumnya pada siklus I. Berikut hasil pembelajaran Siklus II Tabel 6. Aktivitas Belajar Siklus II

\begin{tabular}{cccc}
\hline Aktivitas & Baik & Cukup & Kurang \\
\hline Frekuensi & 21 & 0 & 0 \\
Persentase & $100 \%$ & $0 \%$ & $0 \%$ \\
\hline
\end{tabular}

Hal-hal penting dan perkembangan kemajuan pada saat pembelajaran siklus I meliputi penguasaan materi pengajaran dan kemajuan serta aktivitas peserta didik saat pembelajaran.

Berikut hasil pembelajaran siklus II meliputi aktivitas peserta didik seperti Minat dan motivasi belajar persentase mencapai $100 \%$ Memperhatikan pelajaran yang diberikan $100 \%$, dan Kemampuan menyelesaikan tugas yang diberikan mencapai $100 \%$ untuk kriteria Baik sehingga tujuan pembelajaran telah tercapai dengan Menggunakan Metode Drill berjalan dengan baik, 
ehingga penelitian ini cukup sampai pada siklus II, sajat. Berikut Diagram aktivitas Pembelajaran siklus II :

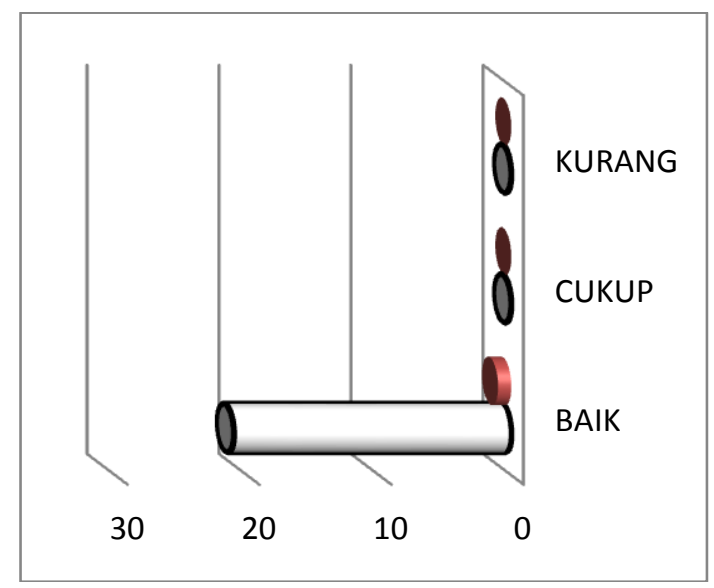

Gambar 6. Aktivitas belajar siklus II

Berikut hasil pembelajaran siklus II setelah dilakukan tindakan pembelajaran dengan metode pembelajaran Menggunakan Metode Drill :

Tabel 7. Hasil pembelajaran siklus II

\begin{tabular}{clcc}
\hline No & Kode Peserta Didik & Nilai & Ketuntasan \\
\hline 1 & ADIT M. SAPUTRA & 80 & tuntas \\
2 & AFRIZAL & 70 & tuntas \\
3 & AHMAD FADILAH & 75 & tuntas \\
4 & ALI SAID & 65 & tuntas \\
5 & ALISA & 70 & tuntas \\
& AMINUL & & \\
6 & HUSNAWATI & 84 & tuntas \\
7 & AULIA ARISQA & 68 & tuntas \\
8 & AULIA SAPITRI & 80 & tuntas \\
9 & DESI & 70 & tuntas \\
10 & EDI & 65 & tuntas \\
11 & ERLIN ERLIANA & 75 & tuntas \\
12 & KADIRAN & 80 & tuntas \\
13 & MARIYA ULFAH & 82 & tuntas \\
14 & MEILIYA HIDAYAT & 78 & tuntas \\
15 & NABILA & 78 & tuntas \\
& NAURA SAL & & \\
16 & SABILLA & 80 & tuntas \\
17 & PUTRI NUR DANDI & 82 & tuntas \\
18 & PUTRI NUR VIKA & 66 & tuntas \\
& REMANIA & & tuntas \\
19 & RAHMADANI & 78 & tuntas \\
20 & RIFAN NURYANDA & 79 & tuntas \\
21 & RIMA RIMBANI & 80 & \\
& RATA-RATA & 75.48 & \\
\hline
\end{tabular}


Berdasarkan hasil pembelajaran siklus II diperoleh nilai rata-rata pembelajaran dari 71,9 meningkat menjadi 75,0 dengan persentase ketuntasan 100\%. Brikut diagram ketuntasan belajar siklus II :

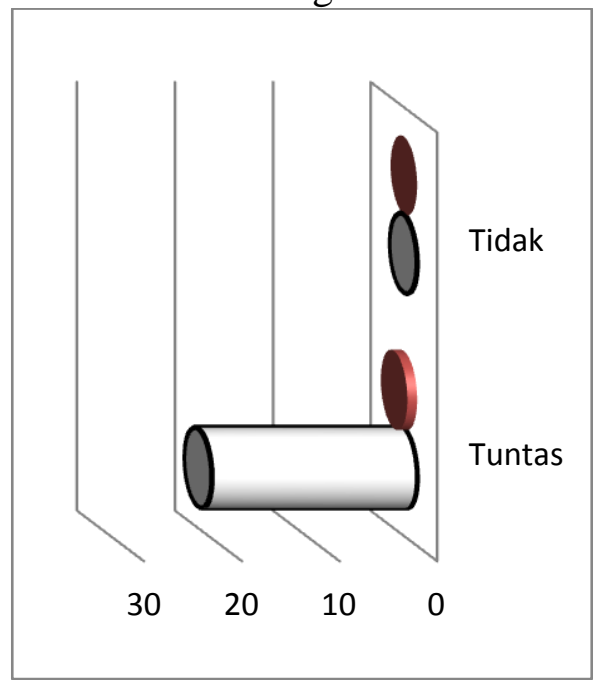

\section{Gambar 7. Ketuntasan Hasil Belajar Siklus II}

Penilaian berdasarkan pengamatan oleh observer berdasarkan perkembangan kemajuan dinilai berhasil jika memenuhi kriteria yang telah ditetapkan yaitu ketercapaian pembelajaran memenuhi persentase $\geq 85 \%$ peserta didik sudah memahami konsep yang disampaikan melalui metode pembelajaran Menggunakan Metode Drill ada peningkatan kemampuan dan memenuh standar ketuntasan sekolah yaitu $\geq 85 \%$ tuntas.

\section{KESIMPULAN DAN SARAN}

\section{Kesimpulan}

Berdasarkan hasil observasi dan tes hasil pembelajaran sebagai bahan evaluasi pembelajaran siklus I dan II maka diperoleh kesimpulan:

Ada hasil pembelajaran pada pembelajaran awal sebelum tindakan persentase ketuntasan adalah $52 \%$, dengan dilakukannya tindakan pembelajaran metode pembelajaran Menggunakan Metode Drill pada siklus I meningkat menjadi $67 \%$, dan pada siklus II dengan persentase aktivitas pemBelajaran memenuhi standar ketuntasan efektifitas belajar mencapai $100 \%$. Ada Peningkatan hasil pembelajaran data awal diperoleh nilai rata-rata pembelajaran dari 69,33 pra tindakan pembelajaran, setelah dilaksanaan pembelajaran dengan metode Menggunakan Metode Drill meningkat menjadi 71,62 pada siklus I dengan persentase ketuntasan $67 \%$. Pada Siklus II rata-rata nilai meningkat menjadi 75,48.

\section{Saran}

Berdasarkan tujuan penelitian hasil penelitian Tindakan Kelas (PTK) dari kesimpulan diatas maka untuk solusi pembelajaran Bahasa Indonesia Kelas II yang mengalami kendala pembelajaran dengan kesulitan belajar pada materi mengenal bagian-bagian utama tubuh hewan dan tumbuhan, pertumbuhan hewan dan tumbuhan, serta tempat hidup makhluk hidup, dilakukan inovasi pembelajaran dengan menggunakan metode pembelajaran Menggunakan Metode Drill untuk memperoleh ketuntasan $\geq 85 \%$ karena hasilnya sangat signifikan. Direkomendasikan sesuai manfaat penelitian sebagai berikut; 
1. Bagi guru Kelas II agar bisa melakukan pembelajaran yang inovatif guna mengatasi masalah pembelajaran dan dapat digunakan sebagai referensi metode pembelajaran menggunakan Metode Drill dalam pembelajaran Bahasa Indonesia karana hasil pembelajaran yang baik dapat meningkatkan hasil belajar peserta didik.

2. Bagi kepala sekolah, agar dapat merekomendasikan kepada guru Kelas II maupun guru lain agar melakukan inovasi pembelajaran apabila mengalami masalah pembelajaran guna meningkatkan kompetensi tenaga pengajar dan dapat mengatasi kesulitan belajar peserta didik, terutama di SDN 1 Sungai Undang. Kecamatan Seruyan Hilir Kabupaten Seruyan.

\section{DAFTAR PUSTAKA}

Arikunto, S. 2008. Penelitian Tindakan Kelas. Jakarta: Bumi Aksara.

Allyn \& Bacon. Gulő, W. 2000. Strategi Belajar Mengajar. Jakarta: Gramedia.

Bell Gredler, E. Margaret. 1991. Belajar dan Membelajarkan. Jakarta: CV. Rajawali

Darsono, Max, dkk. 2000. "Belajar dan Pembelajaran". Semarang : CV. IKIP Semarang Press.

Depdiknas. 2002. Kurikulum Berbasis Kompetensi. Ringkasan Kegiatan Belajar Mengajar. Jakarta:

Degeng, I Nyoman Sudana. 1989. Ilmu Pengajaran Taksonomi Variable. Jakarta: Depdikbud

Eggen, P.D. \& Kauchak, D.P. 1996. Strategies for Teacher: Teaching Content and Thinking Skill

Gagne, E.D., 1985. The Cognitive Psychology of School Learning. Boston, Toronto: Little, Brown and Company

Hasan, Ch. 1994. Dimensi-Dimensi Psikologi Pendidikan. Surabaya: Al- Ikhlas. Irawati, DE. 2003

J. \& S. Nasution. 2002. Mengajar dengan Sukses. Jakarta: Bumi Aksara.

Light, G. \& Cox, R. 2001. Learning and Teaching ini Higher Education. London: Paul Chapman Publising

Moll, L. C. (Ed.). 1994. Vygotsky and Education: Instructional Implications and Application of Sociohistorycal Psychology. Cambridge: Univerity Press

Purwanto, N. 1997. Psikologi Pendidikan. Bandung: PT. Remaja Rosdakarya.

Sudjana, N. 1989. Cara Belajar Peserta didik Aktif dalam Proses Belajar Mengajar. Bandung: Sinar Baru Algensindo.

Slavin, R.E. 2000. Educational Psychology: Theory and Practice. Sixth Edition. Boston: Allyn and Bacon 